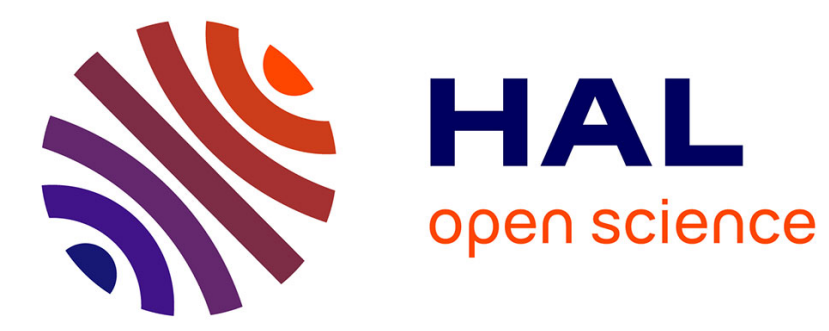

\title{
Structure of concentrated nonionic surfactant microemulsions studied by small angle neutron scattering
}

\author{
L. Liz Marzán, J. Samseth, M. López Quintela
}

\section{- To cite this version:}

L. Liz Marzán, J. Samseth, M. López Quintela. Structure of concentrated nonionic surfactant microemulsions studied by small angle neutron scattering. Journal de Physique IV Proceedings, 1993, 03 (C8), pp.C8-165-C8-168. 10.1051/jp4:1993832 • jpa-00252263

HAL Id: jpa-00252263

https://hal.science/jpa-00252263

Submitted on 1 Jan 1993

HAL is a multi-disciplinary open access archive for the deposit and dissemination of scientific research documents, whether they are published or not. The documents may come from teaching and research institutions in France or abroad, or from public or private research centers.
L'archive ouverte pluridisciplinaire HAL, est destinée au dépôt et à la diffusion de documents scientifiques de niveau recherche, publiés ou non, émanant des établissements d'enseignement et de recherche français ou étrangers, des laboratoires publics ou privés. 


\title{
Structure of concentrated nonionic surfactant microemulsions studied by small angle neutron scattering
}

\author{
L. LIZ MARZÁN ${ }^{(1)}$, J. SAMSETH* and M.A. LÓPEZ QUINTELA
}

\author{
Departamento de Química Física, Universidade de Santiago, 15706 Santiago de Compostela, Spain \\ * Institutt for Energiteknikk, P.O. Box 40, 2007 Kjeller, Norway
}

\begin{abstract}
: the structure of the microemulsion system consisting of $40 \%$ in volume of the nonionic surfactant pentaethyleneglycol-4-octylphenyl ether and equal volumes of decane and of the aqueous phase, has been studied by means of Small Angle Neutron Scattering (SANS) and electrical conductivity experiments. The influence of several kinds of additives present in the aqueous phase ( $\mathrm{KCl}$, sodium dodecyl sulphate, and n-butanol) on the microstructure of the system at different temperatures has also been studied. SANS experiments revealed the existence of a water-in-oil structure with droplet sizes of the order of $2.6 \mathrm{~nm}$ and polydispersity around $20 \%$ in mostly all the cases. A slight increase in the distance between droplets with the addition of $\mathrm{KCl}$ can be observed, while the addition of SDS or nbutanol results in smaller size and polydispersity. High electrical conductivity values have been obtained for the samples with salts, which can be due to interactions induced by the applied electrical field.
\end{abstract}

\section{INTRODUCTION}

The simplest way to describe a microemulsion is as an optically transparent, thermodynamically stable mixture of water, oil and a surfactant (molecule containing a polar head and an nonpolar tail). Sometimes a cosurfactant is needed to help the formation of the microemulsion.

Apart from their appearance, depending on their composition these mixtures can form a variety of different phases (cloudy, lamellar, etc.), existing alone or coexisting with each others, i.e. the phase diagrams can be very rich. Other parameters like temperature, influence to a great extent the distribution of the regions where the different phases exist.

These systems have been used for many applications in different fields, from both a technological and a scientific point of view. For instance, they are used in oil recovery [1], and fine and ultrafine particle preparation $[2,3]$.

The most widely used nonionic surfactants are the so-called long tail $C . E_{\text {, }}$, and the systems in which they are included have been extensively studied [4,5]. The main drawback of such surfactants is their high cost. Therefore, the characterization of microemulsions with nonexpensive, nonionic surfactants is becoming very important. Previous studies on the phase behaviour of the system pentaethylenglycol-4-octyl-phenyl ether/n-decane/water, with different additives [6] revealed the presence of different phases as a function of composition and temperature.

In most of the applications of microemulsions, it is necessary to include in the microemulsion system different concentrations of several salts, what means that we need to know the influence that salt concentration exerts on the phase diagram (temperature shifts, variation of the isotropic domain, etc.). At the same time, it is convenient to have a high droplet concentration, and therefore we have chosen a system with in which the volume ratio between $n$-decane and water equals 1 , so that in the case that the microemulsion is actually formed by droplets, we should get the maximum droplet concentration. For this study, and based on our former studies, we chose the system with $40 \%$ in volume of surfactant.

One can observe for such a composition the existence of a single phase region of liquid crystals ( $\left.\mathrm{L}_{\alpha}\right)$; a twophase region $\left(\mathrm{L}_{\alpha}+\mathrm{L}\right)$ in which a lower liquid crystalline phase $\left(\mathrm{L}_{\alpha}\right)$ coexists with an upper isotropic phase $(\mathrm{L})$; an one-phase isotropic region (L) corresponding to microemulsion; and another two-phase region $(\mathrm{C}+\mathrm{L})$, with a lower cream phase (C) (apparently a white solid) and an isotropic upper phase (L).

An explanation for this behaviour can be found in terms of flexibility and curvature of the surfactantlayers, which increase as temperature does, giving place to the transition from nearly flat layers $\left(\mathrm{L}_{\alpha}\right)$ to microdroplets $(\mathrm{L})$ and finally to dense aggregates of such microdroplets (C).

(1) Permanent address: Van't Hoff Laboratorium voor Fysische en Colloïdchemie, Rijksuniversiteit Utrecht, Postbus 80.051, Padualaan 8, 3508 TB Utrecht, The Netherlands 
With respect to the influence of additives, we have chosen two salts of different nature, namely $\mathrm{KCl}$ and sodium dodecyl sulphate (SDS), which greatly differ in the size of the anion, and a short chain alcohol (n-butanol) that is a standard additive for the modification of the properties of microemulsions.

It was observed that $\mathrm{KCl}$ promotes a shift of the isotropic domain towards lower temperatures due to a lyotropic effect. In the case of SDS, no shift was observed for the $L_{\alpha}$ to $(L+L)$ transition. But a shift towards higher temperatures occurs for the transition from $\mathrm{L}$ to $(\mathrm{C}+\mathrm{L})$, because $S \mathrm{SS}$ molecules lead to an increase in watersurfactant solubility, so that the higher the SDS concentration is, the higher the temperatures are necessary to destabilize the isotropic microemulsion phase. On the other hand, $n$-butanol acts as a cosurfactant, increasing the curvature of surfactant layers and hence promotes a clear shift towards lower temperatures.

In order to get a first approximation of the structure of microemulsions, electrical conductivity measurements can be used. It is well-known that aqueous solutions of salts show appreciable conductivities, while organic compounds (nonpolar) present nearly no conductivity, therefore, in general, $\mathrm{O} / \mathrm{W}$ microemulsions (water phase as a continuous medium) will show high conductivities, while W/O microemulsions (oil as a continuous medium) will show very low conductivities.

But the information that can be obtained by means of electrical conductivity measurements is not enough to know the real structure of our systems, so that it must be complemented with other techniques. Scattering techniques have proven to be specially suitable for the study of colloidal systems [7], and in particular SANS appears to be the most efficient one with respect to microemulsions, due to the very easy contrast variation that can be performed by varying the ratio $\mathrm{H}_{2} \mathrm{O} / \mathrm{D}_{2} \mathrm{O}$ of the aqueous phase.

\section{EXPERIMENTAL}

All the chemicals were supplied by Aldrich, except n-butanol and sodium dodecyl sulphate (SDS), which were supplied by Merck. All of them have been used without further purification. In every case double distilled water was used, which was just substituted by $\mathrm{D}_{2} \mathrm{O}$ for the samples to be measured by SANS.

For the electrical conductivity measurements, a Crison conductivity cell was used. Such a cell was introduced into the sample, which in turn was sumerged into a thermostatic bath what allowed the variation of sample temperature without performing other actions on it. As a measuring instrument, a RCL bridge (Databridge 452) was used.

The small angle neutron scattering (SANS) measurements were performed at the Jeep II reactor of the Institutt for energiteknikk at Kjeller (Norway). The radiation used had a wavelength of $5.5 \AA$, with a distance between sample and detector of $1.56 \mathrm{~m}$, and introducing the sample in quartz cuvettes of $1 \mathrm{~mm}$ optical path length. With this set of parameters, the available range for $\mathbf{Q}(4 \pi \mathbf{n} / \lambda \sin (\theta / 2), \theta$ being the scattering angle, $\lambda$ the wavelength and $\mathbf{n}$ the refractive index of solvent) was from 0.01 to $0.23 \AA^{-1}$, what results in general to be suitable for the observation of the scattering peaks in the studied samples.

Prior to the fit, the data were corrected for the instrumental background and scattering from the empty cuvette, then normalized with respect to $\mathrm{H}_{2} \mathrm{O}$ and integrated. This treatment is described in detail by Chen [7].

\section{RESULTS AND DISCUSSION}

For the fitting of SANS measurements we used Teubner-Strey, hard ellipsoids and polydisperse spheres models.

The model proposed by Teubner and Strey [8] is based on the theory of diffusion in porous media, from which one can derive an expression for the scattering intensity by Fourier transforming the density correlation function:

$$
I(Q)=2 \pi(S / V)\left(\rho_{1}-\rho_{2}\right)^{2}\left\{\left[\xi^{-2}+(2 \pi / d)^{2}\right\}^{2}+2\left[\xi^{-2}+(2 \pi / d)^{2}\right] Q^{2}+Q^{4}\right\}^{-1}
$$

where $S / V$ is the surface to volume ratio of the particle.

The characteristic length $\xi$ is called correlation length, and it is related to the size of the particles. On the other hand, $d$ is usually interpreted as the interdomain-distance in the system. Furthermore, the dimensionless relation $(2 \pi \xi / d)^{-1}$ represents a measure of the polidispersity of the existing domains, showing therefore larger values when the microemulsion system shows a bicontinuous structure [9].

Hard ellipsoids model consists of using the Chen's [7] decoupling theory for the scattering intensity:

$$
I(Q)=n_{p} P(Q)\{1+\beta[S(Q)-1]\}
$$

where $P(Q)=<|F(Q)|^{2}>$ is the intraparticle structure factor, $S(Q)$ is the interparticle structure factor, $F(Q)$ is the form factor of the particle, $n_{p}$ the number density of particles and $\beta=\left\langle F(Q)>\left.^{2}|<| F(Q)\right|^{2}\right\rangle$.

Then we introduce a form factor for ellipsoids:

$$
F(Q, u)=\left(\rho_{1}-\rho_{D}\right) \vee 3 j_{1}(u) / u
$$


where $\rho_{1}$ and $\rho_{\mathrm{D}}$ are the characteristic scattering length densities of the particle and the solvent, respectively, $v$ is the volume of the particle, $j_{1}$ the spherical Bessel function of first order:

$$
\mathrm{j}_{1}(\mathrm{QR})=\frac{\sin (\mathrm{QR})-\mathrm{QR} \cos (\mathrm{QR})}{(\mathrm{QR})^{2}}
$$

and

$$
\mathrm{u}=\mathrm{Q}\left[\mathrm{a}^{2} \mu+\mathrm{b}^{2}(1-\mu)^{2}\right]^{1 / 2}
$$

where $\mu$ is the cosine of the angle between the scattering vector $Q$ and the symmetry axis of the ellipsoid, with major and minor axis a and $b$, respectively.

Using these expressions the intraparticle form factor can be calculated form the following expression:

$$
P(Q)=<|F(Q, \mu)|^{2}>=\int_{0}^{1}|F(Q, \mu)|^{2} d \mu
$$

where the integral must be solved numerically.

In the case of polydisperse spheres, it is necessary to do an averaging over a particle size distribution $f(r)$ and

$$
\mathrm{P}(\mathrm{Q})=\int_{0}^{\infty} \mathrm{F}(\mathrm{Q}, \mathrm{r})_{\text {sphere }}^{2} f(\mathrm{r}) \mathrm{dr}
$$

where $F(Q, r)_{\text {sphere }}$ is the form factor for spheres, i.e. equations (3)-(5) with $\mu=1$. A common $f(r)$ is the Schultz distribution [10], which has the advantage that $P(Q)$ can be solved analiticaly.

For the calculation of the interparticle structure factor, the so-called mean spherical approximation (MSA) [10] is usually utilized. In our case MSA did not work because the attractions in the dispersed phase are very weak, therefore the Percus Yevick approximation for hard spheres was used. It is important to take into account that the decoupling model is not valid if the axial ratio is greater than 2 [7].

The measurements show clear peaks in the chosen Q-range. We could perform reasonably good fits by means of the Teubner-Strey model. The results of such fits are shown in Table 1. The low values obtained for the parameter $(2 \pi \xi / \mathrm{d})^{-1}$ may indicate a droplet-like structure in our system. The fit with the hard ellipsoids model permits to obtain good results. It is remarkable that the obtained values for the volume fraction of the dispersed phase are always very close to that of $\mathrm{D}_{2} \mathrm{O}$, which makes us to think of a W/O structure. The results obtained by these fits are also shown in Table 1. It can be observed in all the cases, except that of the sample with $6 \% \mathrm{n}$ butanol that the minor axis predominates over the major axis, i.e. droplets show a disclike shape, but this may reflect the polydispersity of spherical droplets. Therefore we used the hard spheres model with Schultz distribution for the polydispersity (Figure 1 and Table 1), we get in all the cases average radii around $2.6 \mathrm{~nm}$ and polydispersities around $20 \%$. With this model we get again volume fractions close to those of $\mathrm{D}_{2} \mathrm{O}$. In order to check if the assumption of W/O structure is correct, we diluted a sample without additives, by simply adding oil while keeping constant the water/surfactant ratio, i.e. following a dilution line. When fitting the obtained SANS curve to polydisperse spheres, we get a similar size as before, a longer distance between droplets and again a value of volume fraction very close to the one for water, thus in agreement with our previous assumption.

With respect to the influence of the different kinds of additives, we found that the addition of $\mathrm{KCl}$ increases slightly the distance between droplets, probably due to the effect of the electrical charges that go to the interface. For SDS and n-butanol a decrease in both droplet size and polydispersity is observed. The explanation of this fact can be the disorder introduced by these molecules (with a polar group themselves) at the interface, increasing curvature and promoting the formation of a higher number of droplets, which consequently must be smaller.

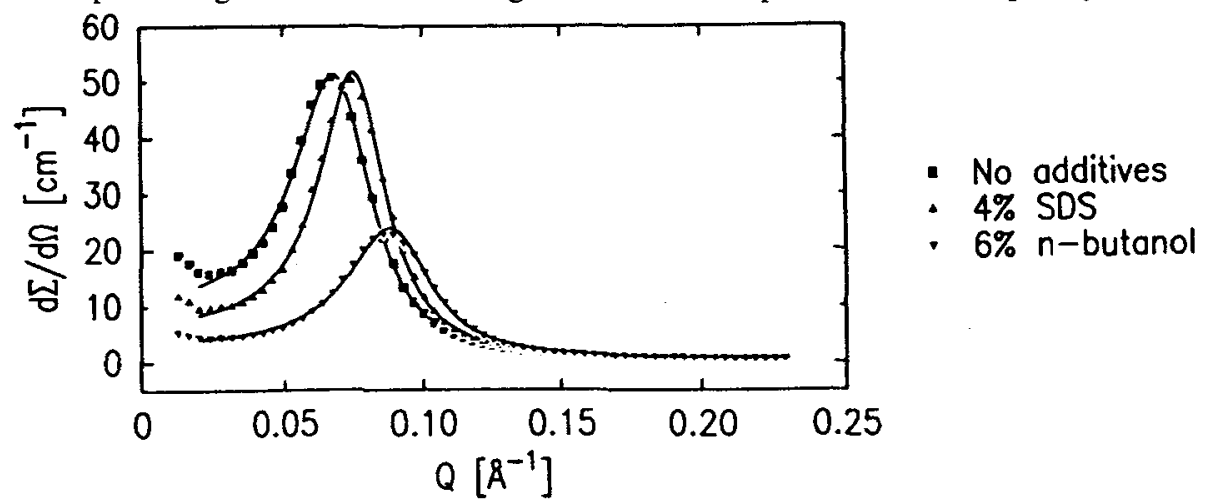

Fig. 1.- Neutron scattering for the system without additives, with $4 \%$ SDS and with $6 \%$ n-butanol. Solid lines represent the fits to the polydisperse hard spheres model. 
Table 1.- Results of neutron scattering measurements according to Teubner-Strey, hard ellipsoids and hard polydisperse spheres models, for the system in the isotropic one-phase region

\begin{tabular}{|c|c|c|c|c|c|c|c|c|c|c|c|}
\hline \multirow[b]{2}{*}{ SAMPLE } & \multirow[b]{2}{*}{$\mathrm{T}\left({ }^{\circ} \mathrm{C}\right)$} & \multicolumn{3}{|c|}{ Teubner - Strey } & \multicolumn{3}{|c|}{ hard ellipsoids } & \multicolumn{4}{|c|}{ polydisperse hard spheres } \\
\hline & & $\begin{array}{c}\text { Corr. } \\
\text { length } \\
(\mathrm{nm})\end{array}$ & $\mathrm{d}(\mathrm{nm})$ & $(2 \pi \xi / \mathrm{d})^{-1}$ & $\begin{array}{c}\text { Minor } \\
\text { axis (nm) }\end{array}$ & $\begin{array}{c}\text { Major } \\
\text { axis }(n m)\end{array}$ & $\begin{array}{c}\text { Int. length } \\
(\mathrm{nm})\end{array}$ & $\begin{array}{l}\text { Volume } \\
\text { fraction } \\
(\%)\end{array}$ & $\begin{array}{l}\text { av. radius } \\
(\mathrm{nm})\end{array}$ & $\begin{array}{l}\text { polydisp. } \\
(\%)\end{array}$ & $\begin{array}{c}\text { Int. length } \\
(\mathrm{nm})\end{array}$ \\
\hline \multirow{2}{*}{ no additives } & 44.5 & 6.2 & 8.7 & 0.23 & 4.0 & 2.2 & 8.4 & 31.8 & 2.7 & 23 & 8.5 \\
\hline & 50 & 5.7 & 9.0 & 0.25 & 3.9 & 2.1 & 8.5 & 29.9 & 2.7 & 24 & 8.6 \\
\hline \multirow{2}{*}{$5 \% \mathrm{KCl}$} & 35 & 6.3 & 8.9 & 0.23 & 4.0 & 2.2 & 8.5 & 31.9 & 2.7 & 22 & 8.6 \\
\hline & 40 & 6.0 & 9.1 & 0.24 & 4.1 & 2.2 & 8.6 & 30.4 & 2.7 & 24 & 8.8 \\
\hline \multirow{2}{*}{$4 \%$ SDS } & 48 & 6.7 & 8.2 & 0.19 & 3.7 & 2.1 & 8.1 & 34.6 & 2.6 & 20 & 8.2 \\
\hline & 56 & 6.6 & 8.4 & 0.20 & 3.8 & 2.1 & 8.2 & 33.9 & 2.6 & 21 & 8.4 \\
\hline $\begin{array}{c}3 \% \mathrm{KCl}+ \\
4 \% \mathrm{SDS}\end{array}$ & 35 & 6.3 & 8.2 & 0.21 & 3.8 & 2.1 & 8.0 & 33.8 & 2.6 & 22 & 8.1 \\
\hline $\begin{array}{c}6 \% \\
\text { n-butanol }\end{array}$ & 25 & 5.5 & 7.0 & 0.20 & 2.2 & 3.6 & 6.8 & 33.4 & 2.2 & 18 & 6.9 \\
\hline
\end{tabular}

Conductivity measurements could help in order to determine the nature of the contiunuous phase.

In the cases of both the system without additives and with n-butanol, we get low values of the conductivity, what can be due to either a W/O structure, or to the absence of salts in these systems (even the surfactant is nonionic). The variation with temperature is extremely small, so that phenomena of structure inversion when varying temperature cannot be observed.

In the case of the systems with $5 \% \mathrm{KCl}$ and $4 \%$ SDS in the water phase, the conductivity shows higher values (of the order of $10^{-3} \mathrm{~S} / \mathrm{cm}$ ), similar to that what an aqueous solution of the same salt could present, which clearly suggests the presence of an $\mathrm{O} / \mathrm{W}$ microemulsion. These observations disagree with SANS measurements, where for all the samples we get a volume fraction of the dispersed phase very close to that of $\mathrm{D}_{2} \mathrm{O}$.

We can try to explain the high conductivity because of the induction of a tunneling effect due to the electrical field applied on the samples when performing the conductivity measurements.

\section{CONCLUSIONS}

We have studied the structure of the microemulsion system pentaethyleneglycol-4-octylphenyl ether/n-decane/ water with a volume ratio 1:1 between oil and water, and $40 \%$ in volume of the surfactant.

SANS experiments showed the existence of a droplet-like water in oil structure in the isotropic phase of this system, and the droplet shape and size have been characterized as polydisperse hard spheres with an average radius of the order of $2.6 \mathrm{~nm}$ and polydispersity of the order of $20 \%$. It was observed as well that the size of the microdroplets hardly changes with temperature or additives, except that $\mathrm{KCl}$ increases the distance between droplets and both SDS and n-butanol decrease droplet size and polydispersity.

Electrical conductivity turns out to be high for the samples with salts, which disagree with the SANS results. These high values can be the result of electrical field induced interactions in the dispersed phase.

\section{References}

[1] Gotarty W.B., J. Pet. Technol. 28 (1976) 93.

[2] Fendler J.H., Membrane Mimetic Chemistry (John Wiley \& Sons, New York, 1982).

[3] L.opez Quintela M.A., Rivas J., J. Colloid Interface Sci. (1993). In press.

[4] Kahlweit M., Strey R., Firman P., Haase, D., Langmuir 1 (1985) 281.

[5] Kahlweit M., Strey R., J. Phys. Chem. 92 (1988) 1557.

[6] Lopez Quintela M.A., Fernández Nóvoa A.,Quibén J., Liz L. (1993). In preparation.

[7] Chen S., Ann. Rev. Phys. Chem. 37 (1986) 351.

[8] Teubner M., Strey R., J. Chem. Phys. 87 (1981) 3195.

[9] Chen S.H., Chang S.L., Strey R., Samseth J., Mortensen K., J. Phys. Chem. 95 (1991) 7427.

[10] Hayter J.B., Penfold J., Mol. Phys. 42 (1981) 109. 